\title{
Desempenho de bezerros da raça Holandesa alimentados com proteína de soja sólida ou líquida ${ }^{1}$
}

\author{
Carlos de Sousa Lucci ${ }^{2}$, Edison Valvasori ${ }^{3}$, Valter Fontolan², Kleber da Cunha Peixoto \\ Júnior ${ }^{2}$, Arthur Alonso Almeida Souza ${ }^{4}$, Marianne Élen Real de Lima ${ }^{5}$, Gabriel da Rocha \\ Silvestrini ${ }^{5}$
}

\footnotetext{
1 Pesquisa financiada pela FAPESP - processo: 01/13798-3.

2 Universidade de Santo Amaro.

${ }^{3}$ Instituto de Zootecnia ACTA - Secretaria da Agricultura do Estado de São Paulo.

${ }^{4}$ Mestrando Faculdade de Medicina Veterinaria e Zootecnia USP.

5 Médico Veterinário.
}

RESUMO - Avaliaram-se os efeitos da substituição de metade do total de proteína da dieta na forma sólida (farelo de soja) por proteína na forma líquida (leite de soja), com relações sólidos:líquidos de 100,0:0\%; 87,5:12,5\%; e 75,0:25,0\%. Utilizaram-se 24 bezerros machos da raça Holandesa com 60 dias de idade, distribuídos em delineamento em blocos ao acaso, com três dietas à base de concentrado (80\%) e feno de capim coast-cross (Cynodon dactylon) (20\%), balanceadas para nitrogênio e energia. Nas dietas com partes líquidas, o intuito foi manter o reflexo de formação da goteira esofagiana no período experimental de 10 meses, no qual os animais foram mantidos em confinamento, sendo abatidos ao atingirem pesos corporais superiores a $400 \mathrm{~kg}$. Em alguns dos animais, dotados de cânulas de rúmen, foi possível detectar neste órgão apenas pequenas quantidades do leite de soja ingerido, confirmando sucesso na formação da goteira esofagiana. Os ganhos de peso diários apresentaram redução linear (1,399; 1,341; e 1,191 kg) à medida que foram fornecidas maiores quantidades de leite de soja. As conversões de matéria seca e proteína bruta em ganhos de peso, durante os últimos 60 dias experimentais, pioraram conforme aumentaram as quantidades de proteína na forma líquida. O fornecimento de proteína na forma líquida na dieta não altera os rendimentos de carcaça em bezerros holandeses.

Palavras-chave: abate precoce, alimentação líquida, bovinos leiteiros, conversão alimentar, ganho de peso, goteira esofagiana

\section{Performance of Holstein calves fed soybean meal protein in solid or liquid form}

\begin{abstract}
The effects were assessed of substituting half the total diet protein in solid form (soybean meal) with liquid form (soybean milk) at solid:liquid ratios of: 100.0:0\% L; 87.5:12.5\% L; 75.0:25.0\% L. Twenty-four Holstein breed 60-d male calf steers were assigned to a randomized block design, with three concentrate (80\%) diets and 20\% coast-cross (Cynodon dactylon) hay, balanced for nitrogen and energy. In the diets with liquid parts, the intention was to keep the functional reflex of the esophageal groove throughout the 10 months of the experimental period, in which the animals were kept in a feedlot until slaughter at body weights higher than $400 \mathrm{~kg}$. In some of the animals, with rumen canulas, only small quantities of ingested soybean milk were detected in the rumen contents, indicating success in esophageal groove formation. Daily weight gains were linearly reduced $(1.399,1.341$ and $1.191 \mathrm{~kg}$ ) as the treatments supplied larger quantities of soybean milk. Dry matter and crude protein conversions in weight gains, in the last 60 days of the experimental period, declined as the proportions of liquid feed increased. Supplying protein in liquid form in the diet did not alter carcass yield in Holstein steer.
\end{abstract}

Key Words: dairy cattle, early slaughter, esophageal groove, feed conversion, liquid feeding, weight gain

\section{Introdução}

Entre os nutrientes necessários para o máximo desenvolvimento de um bezerro jovem, os aminoácidos provenientes da proteína alimentar são os de maior importância (Bagg et al., 1985). Estudos mais antigos sobre a utilização de fontes proteicas de alto valor nutricional, como farinha de peixe (Huber \& Slade, 1967), proteína do leite e produtos da soja (Nitsan et al., 1971; 1972) confirmam as vantagens do emprego de proteína de melhor valor biológico na velocidade de crescimento desses animais. 
Em trabalhos mais recentes, quanto menos degradáveis as proteínas dietéticas, melhor o desempenho dos animais, fato atribuído ao aproveitamento da fração proteica que alcança o intestino sem ser alterada em sua passagem pelo rúmen (Iriki et al., 1992; Bunting et al., 1996; Sampath \& Sivaraman, 1986). Swartz et al. (1991) também observaram melhor desempenho quando acrescentaram maiores proporções de proteína não-degradável no rúmen em dietas para bezerros Holandeses com 14 a 25 semanas de idade. Reddy et al. (1993) observaram maiores consumos e ganhos de peso e melhor eficiência alimentar em animais que receberam proteína de soja com menor degradabilidade ruminal. Sampath \& Sivaraman (1986), empregando fontes de proteína não-degradável no rúmen para bezerras mestiças de 4 a 6 meses de idade, concluíram que a inclusão dessa proteína melhorou os ganhos de peso nesta categoria animal.

Apesar da importância da proteína não-degradável no rúmen, não é menos necessária a presença da fração degradável, decomposta até nitrogênio amoniacal, em razão do seu papel no equilíbrio da ecologia do rúmen. A microbiota ruminal, composta principalmente de protozoários e bactérias, caracteriza-se pelo fato de que 82\% das bactérias utilizam amônia como fonte de nitrogênio, enquanto 25\% não sobrevivem com outras fontes (Van Soest, 1983); além disso, necessitam de um ambiente com quantidade de nitrogênio amoniacal próxima a $5 \mathrm{mg} / 100 \mathrm{~mL}$ de conteúdo de rúmen para seu máximo crescimento e atividade (Satter \& Slyter, 1974). Disponibilidade insuficiente de nitrogênio degradável no rúmen limita a fermentação ruminal, diminuindo o consumo e a eficiência energética do alimento quando a maior parte dos carboidratos é digerida pela fermentação pelos microrganismos ruminais (ARC, 1980).

Uma das formas para que nutrientes ultrapassem o rúmen é aquela obtida com êxito pela simples manutenção do funcionamento da goteira esofagiana, conforme registrado por Orskov (1970) com ovinos, Mikhail et al. (1988) com caprinos e Abe et al. (1998) com bovinos. O aproveitamento da manutenção da goteira esofagiana em animais adultos é um método eficiente para administrar nutrientes como aminoácidos essenciais (Iriki et al., 1992; Abe et al., 1998) ou lipídeos (Spanski et al., 2007).

Outro fator relevante em estudos dessa natureza é o melhor conhecimento sobre as qualidades das carcaças de animais da raça Holandesa submetidos a sistema de alimentação para abate precoce (Swartz et al., 1991; Drevjany, 1989).

O objetivo neste estudo foi verificar se a administração da proteína de soja na forma líquida com destino à digestão intestinal via goteira esofagiana resultaria em maiores taxas de crescimento em novilhos de raças leiteiras destinados ao abate precoce.

\section{Material e Métodos}

Dezoito bezerros da raça Holandesa, não-castrados, foram distribuídos logo após o desaleitamento aos 60 dias de idade em um delineamento em blocos ao acaso (Gomes, 1980). A intenção foi avaliar três dietas, formando três blocos de seis indivíduos, considerando o tempo, com repetição dentro de bloco. Um grupo diferenciou-se pelo fato de os seis animais possuírem cânulas de rúmen, inseridas cirurgicamente aos 4 meses de idade. As dietas foram balanceadas para serem isonitrogenadas e isoenergéticas e diferiram apenas quanto à proporção de proteína de soja, fornecida na forma sólida ou líquida. Nas dietas, metade da quantidade de proteína bruta (PB) foi fornecida na forma sólida (farelo de soja) ou na forma líquida (leite de soja), nas proporções: 100:0; 87,5:12,5; e 75,0:25\%. Considerando a possibilidade de o alimento fornecido na forma líquida passar diretamente ao abomaso e intestino, e empregando-se estimativas de taxas de degradabilidade dos alimentos sólidos (NRC, 1989) as dietas foram formuladas com 24, 32 e $40 \%$, respectivamente, da proteína dietética como porções não-degradadas no rúmen.

Todos os animais receberam $80 \%$ da matéria seca ingerida como alimentos concentrados e $20 \%$ como feno de coast cross (Cynodon dactylon), de qualidade inferior (níveis menores que 5\% de PB), como fonte de fibra.

As dietas experimentais continham quantidades idênticas de mesma mistura de concentrados, com aproximadamente $12 \%$ de $\mathrm{PB}$ ou equivalente proteico, que compunham 50\% do total de PB fornecido aos animais. A estas quantidades eram acrescidos os $50 \%$ restantes como proteína de soja, obedecendo diferentes proporções de formas sólida e líquida (Tabela 1).

A fração proteica fornecida pelo feno de capim coast cross foi desconsiderada nos cálculos de nutrientes, em virtude de sua pequena contribuição para a fração nitrogenada da alimentação. As quantidades de soja fornecidas na forma líquida variaram de 6 a 16 litros por animal e por dia do início ao final do experimento.

A proteína de soja na forma líquida era oferecida com 2,5\% de PB na dieta 25,0\%L e diluída com água 1:2 na $12,5 \% \mathrm{~L}$, ficando com teor proteico reduzido para $1,25 \%$. Essas diferentes concentrações de PB permitiram oferecer quantidades pré-estipuladas de proteína com quantidades iguais de líquido. 
Tabela 1 - Composição em ingredientes no concentrado, proteína bruta (PB) e proporções de PB fornecidas no concentrado (50\%), no farelo de soja e proteína líquida de soja nas dietas

\begin{tabular}{|c|c|c|c|}
\hline Ingrediente & $\% \mathrm{MN}$ & \multicolumn{2}{|c|}{$\mathrm{PB} / \% \mathrm{MN}$} \\
\hline Farelo de soja & 4,00 & \multicolumn{2}{|c|}{1,84} \\
\hline Milho & 91,25 & \multicolumn{2}{|c|}{7,30} \\
\hline Uréia & 1,00 & \multicolumn{2}{|c|}{2,81} \\
\hline Bicabornato de Sódio & 1,00 & \multicolumn{2}{|c|}{-} \\
\hline Monensina sódica & 0,75 & \multicolumn{2}{|c|}{-} \\
\hline \multirow[t]{3}{*}{ Mistura concentrada } & 100,00 & & \\
\hline & \multicolumn{3}{|c|}{ Dieta } \\
\hline & $0.00 \% \mathrm{~L}$ & $12.50 \% \mathrm{~L}$ & $25.00 \% \mathrm{~L}$ \\
\hline Farelo de soja & 50,0 & 37,5 & 25,0 \\
\hline Proteína de soja* & 0,0 & 12,5 & 25,0 \\
\hline
\end{tabular}

*Proteína de soja (forma líquida, matéria natural).

O manejo compreendeu: alimentação fornecida duas vezes ao dia, às $8 \mathrm{~h}$ e às $15 \mathrm{~h}$, com controle diário individual de consumo de alimentos por meio de pesagens de ofertas e refugos. As pesagens dos animais foram feitas a cada 28 dias, sempre no mesmo horário, antes da primeira refeição do dia e após jejum prévio de água e alimentos por 12 horas. Nessa ocasiões, foram tomadas medidas de altura às cernelhas e colhidas amostras de sangue por punção da veia jugular. Posteriormente às pesagens, quando necessário, foram corrigidas as quantidades de oferta dos alimentos, tomando-se por base as exigências proteicas (NRC, 1989) para bovinos machos de grande porte. As reformulações foram feitas por bloco, considerando os ganhos de peso médios dos animais dentro do bloco.

O leite de soja, ou proteína de soja na forma de solução, proveniente de grãos de mesma partida, foi confeccionado diariamente. Após moagem fina, a proporção de $1 \mathrm{~kg}$ dos grãos para 6 kg de água era colocada em recipiente metálico provido de pás para agitação permanente e a mistura era mantida a temperaturas entre 80 e $90^{\circ} \mathrm{C}$ durante 30 minutos. Seu fornecimento foi feito na temperatura de $36{ }^{\circ} \mathrm{C}$, em baldes abertos, com intenção de manter funcional o reflexo de formação da goteira esofagiana.

Amostras de feno e mistura concentrada comum a todos os tratamentos e farelo de soja foram colhidas mensalmente. Análises laboratoriais dos teores proteicos do leite de soja eram feitas quinzenalmente para manter homogeneidade entre partidas, especialmente quanto ao leite de soja (Tabela 2).

Com a finalidade de averiguar se nas dietas parcialmente líquidas os reflexos de formação das goteiras esofagianas permaneciam ativos no transcurso do ensaio, quatro animais dotados de cânulas de rúmen, em três idades diferentes (7, 9 e 11 meses), receberam leite de soja adicionado de indicador de fase líquida (polietilenoglicol, peso molecular 4000 - PEG 4000), conforme técnica descrita por Hyden (1956). A quantidade do indicador detectada no conteúdo ruminal indicou a porcentagem do alimento líquido que não transpôs este órgão. Três dias antes dessa observação, 100 g de PEG 4000 foram inseridos no rúmen dos animais canulados pela manhã, após 12 horas de jejum de alimentos e água. Foram colhidas amostras nos tempos zero (antes da administração), 1, 2, 3, 6, 12 e 24 horas. Com os dados obtidos, foi calculada curva da concentração de PEG no líquido ruminal durante as 24 horas após a administração, obtendo-se o volume de líquido no rúmen. No dia da observação, os mesmos animais foram submetidos a jejum prévio de 12 horas e receberam $100 \mathrm{~g}$ de PEG-4000 em mistura aos primeiros 2 litros de leite de soja da refeição matutina. Decorridos 20 minutos, foi colhida amostra de líquido ruminal para análise da presença do indicador.

O período experimental estendeu-se por 10 meses, durante o qual os animais permaneceram confinados. O abate foi realizado quando os animais atingiram pesos

Tabela 2 - Composição nutricional (\%MS) dos ingredientes no concentrado

\begin{tabular}{lcccccc}
\hline Alimento & Matéria seca & Proteína bruta & Extrato etéreo & Fibra em detergente ácido & Fibra bruta & Matéria mineral \\
\hline Mistura & 90,9 & 12,96 & 1,01 & 41,14 & - & 5,87 \\
Farelo de soja & 89,8 & 45,79 & 1,35 & - & 6,25 & 5,65 \\
Leite de soja & 14,3 & 19,46 & - & - & - & - \\
Palha & 87,1 & 3,33 & - & 42,48 & 7,81 \\
\hline
\end{tabular}


vivos superiores a $400 \mathrm{~kg}$. Nesta ocasião, registraram-se pesos e rendimentos de carcaça, além de teste de maciez em bifes retirados do músculo longissimus dorsi entre a $12^{\mathrm{a}}$ costela e a $5^{\underline{a}}$ vértebra lombar. As peças foram submetidas à maturação por 14 dias, a temperaturas entre 0 e $3{ }^{\circ} \mathrm{C}$ para, então, serem cosidas e mensuradas quanto à maciez.

Os resultados foram analisados pelo programa computacional Statistical Analysis System (SAS Institute Inc., 1985), verificando-se anteriormente a normalidade dos resíduos pelo teste de Shapiro-Wilk (PROC UNIVARIATE) e a homogeneidade das variâncias comparadas pelo teste qui quadrado (Comando SPEC do PROC GLM). Parte dos dados foi submetida à análise de regressão do tipo polinomial (utilizando PROC REG) para avaliar efeitos das quantidades de proteína bruta das rações nas formas sólida (farelo de soja) ou líquida (leite de soja) sobre os ganhos de peso, as ingestões de proteína bruta e de matéria seca, as conversões de proteína bruta e de matéria seca em ganhos de peso, os níveis sanguíneos de ureia e glicose e a contagem de leucócitos. Foi realizada também análise de variância (PROC GLM) para avaliar efeitos dos tratamentos sobre as médias diárias de ganhos de peso, as alturas às cernelhas e perímetros torácicos, bem como os rendimentos de carcaça, empregando-se em seguida o teste Tukey para comparação entre médias. $\mathrm{O}$ nível de probabilidade $\mathrm{p}=0,05$ foi adotado para todas as análises realizadas.

\section{Resultados e Discussão}

Como um dos objetivos no trabalho foi avaliar os efeitos de transposição da proteína de soja pelo rúmen por meio de administração de dietas líquidas e da manutenção da funcionalidade da goteira esofagiana, uma primeira questão seria constatar se a goteira permaneceu funcional, considerando a duração do experimento e a idade dos animais (Tabela 3).

Os mesmos bovinos apresentavam 7 meses de idade na primeira prova, 9 meses na segunda e 11 meses na terceira prova. O valor máximo de insucesso correspondeu à detecção no rúmen de 13\% do líquido ingerido, mas em 9 dos

Tabela 3 - Concentrações de PEG (\%) adicionadas ao leite de soja ingerido detectadas no rúmen após 20 minutos de ingestão, em três provas distintas

\begin{tabular}{lccc}
\hline Animal/Tratamento & $\begin{array}{c}\text { Prova 1 } \\
\text { \% PEG }\end{array}$ & $\begin{array}{c}\text { Prova 2 } \\
\text { \% PEG }\end{array}$ & $\begin{array}{c}\text { Prova 3 } \\
\text { \% PEG }\end{array}$ \\
\hline $1 / 12,5 \mathrm{~L}$ & Zero & Zero & Zero \\
$2 / 12,5 \mathrm{~L}$ & 1,6 & 1,5 & Zero \\
$3 / 25,0 \mathrm{~L}$ & 1,5 & 13,0 & 13,0 \\
$4 / 25,0 \mathrm{~L}$ & Zero & 10,0 & Zero \\
\hline
\end{tabular}

12 valores obtidos, a porcentagem de insucesso não excedeu 1,6\% do líquido ingerido. Esses números confirmam que a proteína de soja fornecida na forma líquida transpôs o rúmen e foi direcionada para abomaso e intestino, confirmando os relatos de Orskov (1970) em trabalho com ovinos e de Mikhail et al. (1988) com caprinos. Rodrigues (2000) relatou o bom funcionamento da goteira esofágica em bezerros com 4 a 7 meses de idade recebendo proteína texturizada de soja na forma líquida. Contudo, chamaram a atenção para uma resposta melhor em maior porcentagem de sólidos no alimento líquido. Neste trabalho, constatou-se também que o desempenho com dieta com $25,0 \%$ da proteína na forma líquida teve melhor resposta em alturas e perímetros do tórax em relação à dieta com $12,5 \%$ da proteína na forma líquida, menos rica em sólidos. Já os ganhos de peso não confirmaram essa diferença (Tabela 4). A possibilidade de emprego da goteira esofagiana em animais adultos para administrar aminoácidos essenciais por meio de dietas líquidas foi relatada por outros autores (Iriki et al., 1992; Abe et al., 1998).

O desempenho dos animais não melhorou com o fornecimento das dietas com a proteína de soja na forma líquida, como pode ser observado pelos registros de ganhos de peso, perímetros torácicos e alturas nas cernelhas (Tabela 4).

Para o período experimental de 60 a 360 dias, a equação de predição dos ganhos de peso foi $\widehat{Y}=1,519-0,104$ X com decréscimo de 0,104 kg para cada unidade percentual de proteína fornecida na forma líquida ( $\mathrm{p}=0,004)$. Para o mesmo período, há ainda diferença significativa entre as dietas com $0 \%$ e $25,0 \%$ de proteína na forma líquida $(\mathrm{p}=0,013)$ pelo teste Tukey.

As medições de perímetros do tórax e de alturas nas cernelhas, considerando o total do período de experimentação, também indicam ineficiência da alimentação com dieta líquida. Ganhos em perímetros torácicos e em alturas à cernelha mostraram diferenças significativas entre as dietas com $0 \% \mathrm{~L}$ e $12,5 \% \mathrm{~L}$, que superaram o mais rico alimento líquido, com 25,0\% de proteína líquida ( $\mathrm{p}=0,0003$

Tabela 4 - Ganhos de peso (kg) por animal por dia em vários períodos do experimento; alturas nas cernelhas e perímetros torácicos $(\mathrm{cm})$ dos 60 aos 360 dias de experimentação

\begin{tabular}{cccc}
\hline 60 a 360 dias & 60 a 360 dias & 60 a 360 dias & \\
\cline { 2 - 4 } Proteína líquida & Peso $(\mathrm{kg})$ & Altura $(\mathrm{cm})$ & Tórax $(\mathrm{cm})$ \\
\hline $0 \%$ & $1,399 \mathrm{a}$ & $106,02 \mathrm{a}$ & $128,03 \mathrm{a}$ \\
$12,5 \%$ & $1,341 \mathrm{ab}$ & $105,76 \mathrm{a}$ & $129,54 \mathrm{a}$ \\
$25,0 \%$ & $1,191 \mathrm{~b}$ & $103,45 \mathrm{~b}$ & $124,67 \mathrm{~b}$ \\
\hline
\end{tabular}

Letras diferentes na mesma coluna indicam diferença estatística $(\mathrm{p}<0,05)$. 
e $\mathrm{p}=0,0002$, respectivamente). Como os dados de altura tomados à cernelha apresentam elevada correlação com desenvolvimento esquelético, é possível que os animais alimentados com maiores quantidades de alimento líquido tenham sofrido atraso no desenvolvimento ósseo.

No conjunto, esses resultados podem estar associados ao fato de os animais alimentados com a dieta com 12,5\% da proteína líquida e principalmente com aquela com 25,0\% da proteína líquida terem apresentado vários processos diarreicos. Esses processos provavelmente foram ocasionados por má digestão intestinal da proteína de soja, aliada ao fato de alcançar o intestino de forma abrupta, pela goteira esofagiana, sem coagulação adequada no abomaso que permitisse liberação lenta ao intestino, melhor eficiência enzimática e manutenção de pressão osmótica da digesta. Santos et al. (1998) registraram falhas na obtenção de bons desempenhos com o emprego de rações com proteína nãodegradável no rúmen quando a proteína não apresentava boa digestibilidade intestinal.

Considerando isoladamente os dados referentes aos últimos 60 dias experimentais, análises das médias dos ganhos de peso e das conversões de matéria seca e PB em ganhos de peso mostraram diferenças significativas entre as dietas (Tabela 5), o que evidencia a superioridade do fornecimento de proteína na forma sólida.

Ao comparar os valores obtidos nesta última fase com os apresentados por Silva et al. (2002) com novilhos Nelore de pesos semelhantes e ingerindo rações com $80 \%$ de concentrado, porém com idades diferentes, a conversão alimentar de 6,91 foi próxima aos valores obtidos neste estudo, mas a ingestão de matéria seca, igual a $6,5 \mathrm{~kg}$ por animal por dia, foi bastante inferior.

Durante todo o período experimental, as quantidades de alimento fornecidos foram as mesmas para todas as dietas, sempre respeitando as proporções de $80 \%$ de concentrado e $20 \%$ de volumoso. O direcionamento de parte proteica dos concentrados para digestão intestinal teve como expectativa melhor desempenho, resultante de maior digestibilidade, como encontrado por Burger et al. (2000) para matéria orgânica e carboidratos totais em bezerros Holandeses. Ao contrário, nos últimos meses da experimentação, os ganhos de peso e as conversões de matéria seca e proteína bruta em peso apresentaram médias piores à medida que maiores porções de alimento líquido foram empregadas. Para ganhos de peso, a equação de predição foi $\hat{Y}=1,852-0,170 \mathrm{X}$; para conversão de matéria seca em ganhos de peso $\hat{Y}=0,980+0,225 X$; e para conversão de proteína em ganhos de peso $\hat{Y}=5,491+0,716$ X. Esse fato comprova que a proteína na forma líquida, mesmo via goteira esofagiana, não proporcionou melhor aproveitamento intestinal.

A não-detecção de melhores desempenhos com a passagem direta da proteína pelo rúmen pode estar relacionada a vários fatores. Santos et al. (1998), em artigo de revisão, levantaram hipóteses para falta de resposta à suplementação com proteína sobrepassante por bovinos leiteiros: queda na síntese de proteína microbiana ruminal, fontes de proteína não-degradável inadequadas em aminoácidos essenciais, digestibilidade intestinal baixa dessas fontes e dietas controle já com proteína sobrepassante suficiente. Nesta pesquisa, os efeitos da proteína microbiana ruminal reduziram, fato comum a todas as dietas. A probabilidade de terem ocorrido sobras de proteína não-degradável no rúmen nas dietas empregadas é pequena, a julgar pelo exame das mesmas. Assim parecem mais realistas as possibilidades de a proteína de soja não oferecer equilíbrio ideal em aminoácidos, por apresentar baixos teores de lisina e metionina, reconhecidamente limitantes para o crescimento de animais jovens (Iriki et al., 1992) e ainda de sua digestibilidade intestinal ser inferior ao esperado. Essas possibilidades, de a proteína de soja ao nível de intestino não oferecer aminoácidos em proporções suficientemente boas ou não ser bem digerida, são sustentadas pela falta de respostas no desempenho ao aumento das frações da proteína não-degradada no rúmen de aproximadamente 25\% (0\% de proteína líquida) para 40\% (25,0\% de proteína líquida). No entanto, Swartz et al. (1991) obtiveram velocidades de crescimento mais elevadas e melhor eficiência alimentar ao empregarem maiores porcentagens de proteína não-degradável no rúmen em

Tabela 5 - Ganhos de peso, ingestões de proteína bruta e de matéria seca, conversões de proteína bruta e de matéria seca em ganhos de peso, valores de probabilidade (p) e para regressão (b) e constante (a) das equações de regressão $(\hat{Y}=a+b X)^{1}$

\begin{tabular}{cccccc}
\hline Proteína líquida (\%) & Ganho de peso & Ingestão de PB & Ingestão de MS & Conversão alimentar de PB & Conversão alimentar de MS \\
\hline 0\%L & 1,672 & 2,023 & 10,441 & 1,211 & 6,193 \\
$12,5 \% \mathrm{~L}$ & 1,533 & 2,141 & 10,983 & 1,418 & 6,952 \\
$25,0 \% \mathrm{~L}$ & 1,333 & 2,165 & 10,288 & 1,661 & 7,626 \\
(p) & 0,012 & 0,126 & 0,740 & 0,001 & 0,002 \\
(a) & 1,852 & 1,968 & 10,724 & 0,980 & 5,491 \\
(b) & $-0,170$ & 0,071 & $-0,076$ & 0,225 & 0,716 \\
\hline
\end{tabular}

\footnotetext{
${ }^{1}$ Dados dos últimos 60 dias experimentais.
} 
dietas de bezerros Holandeses com 14 a 25 semanas de idade. Também Sampath \& Sivaraman (1986) concluíram que o emprego de proteína não-degradável no rúmen na alimentação de bezerras mestiças de 4 a 6 meses de idade provocou melhoras nos ganhos de peso.

As análise das amostras de sangue colhidas mensalmente durante o experimento indicou linearidade para teores de ureia $(p=0,0283)$ com equação $\hat{Y}=29,43-1,33 X$. Maiores concentrações de ureia sanguínea obtidas com a dieta sem proteína líquida, quando a proteína foi fornecida na forma sólida, devem ser consequência de aumento dos níveis de $\mathrm{N}-\mathrm{NH}_{3}$ no conteúdo do rúmen, relativamente situações com 12,5\% e 25,0\% de proteína líquida, em que partes da proteína ingeridas na forma líquida passaram diretamente para o intestino. As análises hematológicas também acusaram significância estatística entre tratamentos para números de leucócitos ( $\mathrm{p}=0,008)$, com equação de predição $\hat{Y}=7758,43+660,91$ X, comprovando aumento do seu número por mililitro de sangue em função dos teores de proteína de soja na forma líquida. Esse resultado suporta a hipótese de os processos diarreicos ocasionados pelas dietas com $12,5 \%$ e principalmente por aquela na com
25,0\% da proteína na forma líquida terem sido prejudiciais ao epitélio intestinal e afetado a absorção de nutrientes, com prejuízo para o desempenho, conforme assinalado por Santos et al. (1998) em revisão de experimentos desta natureza.

Embora todos os animais apresentassem pesos vivos muito próximos ao início do experimento, aqueles mantidos com a dieta com $25,0 \%$ da proteína na forma líquida levaram 12 meses para atingir $400 \mathrm{~kg}$, enquanto nos demais o mesmo peso foi atingido com 11 meses ou menos (Tabela 6).

Os rendimentos obtidos, entre 51,96 e 54,42\%, foram inferiores aos relatados por Prado et al. (2000), entre 56,90 e 57,57\% em mestiços Nelore $\times$ Angus com peso vivo médio de $346 \mathrm{~kg}$. Foram também inferiores ao rendimento de 61,3\% descrito por Silva et al. (2002), com novilhos Nelore abatidos com $450 \mathrm{~kg}$ de peso recebendo dieta contendo $80 \%$ de concentrado. Neste estudo a dieta com $12,5 \%$ da proteína líquida superou aquela com 25,0\% em pesos das carcaças. Os pesos dos fígados foram inferiores aos da dieta com 25,0\% da proteína na forma líquida. Contudo, os rendimentos das carcaças e suas características mostraram semelhança estatística.

Tabela 6 - Dados de avaliação de carcaças ${ }^{1}$

\begin{tabular}{lrr}
\hline Variável & $0 \% \mathrm{~L}$ & $12,5 \% \mathrm{~L}$ \\
\hline Idade (meses) & $11,0 \mathrm{a}$ & $10,8 \mathrm{a}$ \\
Peso abate (kg) & $413,71 \mathrm{a}$ & $420,63 \mathrm{a}$ \\
Meia-carcaça direita quente (kg) & $110,83 \mathrm{ab}$ & $114,50 \mathrm{a}$ \\
Meia-carcaça esquerda quente (kg) & $113,00 \mathrm{a}$ & $114,40 \mathrm{a}$ \\
Rendimento de carcaça (\%) & $54,12 \mathrm{a}$ & $54,42 \mathrm{a}$ \\
Meia-carcaça direita fria (kg) & $109,71 \mathrm{ab}$ & $112,93 \mathrm{a}$ \\
Meia-carcaça esquerda fria (kg) & $110,58 \mathrm{a}$ & $112,91 \mathrm{a}$ \\
Trato gastrointestinal cheio (kg) & $67,35 \mathrm{a}$ & $73,14 \mathrm{a}$ \\
$\quad$ Maciez & $1,64 \mathrm{a}$ & $2,21 \mathrm{a}$ \\
Fígado (kg) & $7,08 \mathrm{a}$ & $7,08 \mathrm{a}$ \\
\hline
\end{tabular}

${ }^{1}$ Letras diferentes na mesma linha indicam diferenças $(\mathrm{p}<0,05)$.

\section{Conclusões}

Não é recomendável o emprego de dietas líquidas à base de proteína de soja para melhorar o desempenho dos animais, o rendimento de carcaças e a qualidade de suas carnes. Contudo, o uso de dietas parcialmente líquidas, mantendo a funcionalidade da goteira esofagiana até os 360 dias de idade, abre a possibilidade de explorar essa forma de manejo alimentar em estudos de nutrição.

\section{Referências}

ABE, M.; IRIKI, T.; SHIBUL, H. et al. Comparative nutrition of calves receiving a concentrate diet via rumen or via esophageal groove. Japanese Journal of Zootechnical Science, v.49, n.12, p.889-897, 1998.

AGRICULTUAL RESEARCH COUNCIL - ARC. The nutrient requirements of ruminant livestock. Surrey, 1980. $351 \mathrm{p}$.

BAGG, J.G.; GRIEVE, D.G.; BURTON, J.H. et al. Effect of protein on growth of Holstein heifer calves from 2 to 10 months. Journal of Dairy Science, v.68, n.11, p.2929-2939, 1985.

BUNTING, L.D.; FERNANDEZ, J.M.; FORNEA, R.J. et al. Seasonal effects of supplemental fat or undegradable protein on the growth and metabolism of Holstein calves. Journal of Dairy Science, v.79, n.9, p.1611-1620, 1996.

BURGER, P.J.; PEREIRA, J.C.; COELHO DA SILVA, J.F. et al. Consumo e digestibilidade aparente total e parcial em bezerros Holandeses alimentados com dietas contendo diferentes níveis de concentrados. Revista Brasileira de Zootecnia, v.29, n.1, p.206-214, 2000.

DREVJANY, L.A. Holstein can produce more than milk : beefing qualities of male calves. Highlights of Agricultural Research in Ontario, v.12, n.1, p.6-10, 1989. 
HUBER, J.T.; SLADE, L.M. Fish flour as a protein source in calf milk replacers. Journal of Dairy Science, v.50, n.8, p.1296-1300, 1967.

HYDEN, S. A turbidometric method for the determination of higher polyethylene glycols in biological materials. Lantbr Hogsk Arbb, v.22, n.1, p.139-145, 1956.

IRIKI, T.; ADACHI, K.; ABE, M. Necessity of rumen undegradable dietary protein in 4-5 months old calves under the condition of low protein intake. Animal Science and Technology, v.64, n.4, p.414-419, 1992.

MIKHAIL, M.; BRUGÉRE, H.; LE BARS, H. et al. Stimulated esophageal groove closure in adult goats. American Journal of Veterinary Research, v.49, n.10, p.1713-1715, 1988.

NATIONAL RESEARCH COUNCIL - NRC. Nutrient requirements of dairy cattle. 6.ed. Washington, D.C.: National Academy Press, 1989. 157p.

NITSAN, Z.R.; VOLCANI, R.; GORDIN, S. et al. Growth and nutrient utilization by calves fed milk replacer containing milk or soybean protein concentrate toasted to various degrees. Journal of Dairy Science, v.54, n.9, p.1294-1299, 1971.

NITSAN, Z.R.; VOLCANI, R.; HASDAI, A. et al. Soybean substitute for milk protein in milk replacers for suckling calves. Jornal of Dairy Science, v.55, n.6, p.811-821, 1972.

ORSKOV, E.R.; FRASER, C.; CORSE, E.L. The effect on protein utilization of feeding different protein supplements via the rumen or via the abomasum in young growing sheep. British Journal of Nutrition, v.24, n.3, p.803-809, 1970.

GOMES, F.P. Curso de estatística experimental. Piracicaba: Escola Superior de Agricultura “Luiz de Queiroz”, 1980. 467p.

PRADO, I.N.; PINHEIRO, A.D.; ALCADE, C.R. et al. Revista Brasileira de Zootecnia, v.29, n.6, p.2135-2141, 2000 (supl. 1).

REDDY, P.V.; MORRILL, J.L.; BATES, L.S. Effect of roasting temperatures on soybean utilization by young dairy calves. Journal of Dairy Science, v.76, n.5, p.1387-1393, 1993.

RODRIGUES, R.R. Efeito da administração de proteína de soja, na forma líquida, sobre desempenho e fermentação ruminal em novilhos com goteira esofágica funcional. 2000. 103f. Dissertação (Mestrado em Nutrição Animal) Faculdade de Medicina Veterinária e Zootecnia/Universidade de São Paulo, Pirassununga.

SAMPATH, K.T.; SIVARAMAN, E. Effect of feeding rations with different levels of rúmen degradable protein on growth and digestibility of nutrient crossbred calves. Journal of Veterinary Science, v.17, n.2, p.8-14, 1986

SANTOS, F.A.P.; SANTOS, J.E.P.; THEURER, C.B. et al. Effects of rumen undegradable protein on dairy cows performance: a 12 year review. Journal of Dairy Science, v.81, n.12, p.3182-3213, 1998.

SATTER, L.D.; SLYTER, L.L. Effect of ammonia concentration on ruminal microbial protein production in vitro. British Journal of Nutrition, v.32, n.2, p.199-208, 1974.

SILVA, F.F.; VALADARES FILHO, S.C.; ITAVO, L.C.V. et al. Consumo, desempenho, características de carcaça e biometria do trato gastro intestinal e dos órgãos internos de novilhos Nelore recebendo dietas com diferentes níveis de concentrados e proteína. Revista Brasileira de Zootecnia, v.31, n.4, p.1849-1864, 2002

SISSONS, J.W.; NYRUP, A.; KILSHAW, P. et al. Ethanol denaturation of soybean protein antigens. Journal of the Science of Food and Agriculture, v.33, n.8, p.706-710, 1982.

SPANSKI, N.A.; DRACLEY, J.K.; DAVIS, C.L. et al. Utilization of supplemental triglycerids of free fatty acids by calves from 4 to 10 weeks of age. Journal of Dairy Science, v.80, n.3, p.573-585, 1997.

STATISTICAL ANALYSIS SYSTEM - SAS. SAS User's guide: statistics. 5.ed. Cary: SAS Institute, 1985. (CD-ROM).

SWARTZ, L.; HEINRICHS, A.J.; VARGA, G.A. et al. Effect of varying dietary undegradable protein on dry matter intake, growth and carcass composition of Holstein calves. Journal of Dairy Science, v.74, n.11, p.3884-3891, 1991.

VAN SOEST, P.J. Nutritional ecology of the ruminant. 2.ed. Oregon: O \& Books, 1983. 374p. 